\title{
STRUCTURE AND DYNAMICS OF A NARROW HYBRID ZONE BETWEEN GEOCRINIA LAEVIS AND G. VICTORIANA (ANURA : LEPTODACTYLIDAE) IN SOUTH-EASTERN AUSTRALIA
}

\author{
D. F. GARTSIDE*, M. J. LITTLEJOHN† and G. F. WATSON† \\ * Department of Genetics, $\uparrow$ Department of Zoology; University of Melbourne, Parkville \\ Victoria, 3052, Australia
}

Received 2.v.79

\begin{abstract}
SUMmary
A transect was established across the hybrid zone between Geocrinia laevis and G. victoriana near its southern (coastal) limit. Three diagnostic components of the phenotype, breeding-call structure and two muscle protein systems, were used to analyse the interaction between these parapatric, morphologicallysimilar species.

The zone, based on breeding-call structure, is narrow (9-30 km), with most of the replacement occurring over $2 \mathrm{~km}$. Contact samples consist of putative parental individuals and recombination products, so that this section of the zone may be described as an overlap with hybridisation. This contrasts with an earlier analysis of a transect near the northern (inland) limit of the zone, where there is a narrow intergradation with hybrids predominating in the replacement populations.

In the southern transect, the two muscle protein systems have much broader zones of replacement than that for breeding calls (minimum widths of 33 and $72 \mathrm{~km}$ ). The muscle protein zones are in different geographic positions from each other, and there is little overlap with the zone based on breeding calls.

The patterns of replacement of the three characters in these species appear to be independent of one another, and emphasise the complex nature of hybrid zones.
\end{abstract}

\section{INTRODUCTION}

HYBRID zones are interactions between populations which have diverged genetically so that interbreeding between individuals from the divergent populations results in progeny recognisably different from the parents (hybrids sensu Short, 1969). Initial divergence of populations may occur either while they are still in genetic contact (Alexander and Bigelow, 1960; Jain and Bradshaw, 1966; Bush, 1969; Antonovics, 1971; Endler, 1973, 1977), or during geographic isolation (Mayr, 1963; Dobzhansky, 1970). It is seldom possible to tell whether a hybrid zone is the result of a primary interaction, or of the secondary contact of previously isolated populations.

Although hybridisation may be a transient phenomenon, followed by fusion of the divergent populations, or by broad overlap without hybridisation, most hybrid zones persist and remain relatively stable through time (Moore, 1977 and examples therein). These hybrid zones appear to be of two kinds: (a) those in which hybrids are less fit than either parental type (hybrid disadvantage) (e.g. Watson, 1972), and (b) those in which hybrids are more fit than either parental type (hybrid advantage), but less fit in adjacent parental areas (e.g. Hagen, 1967). Type (a) hybrid zones will be 
characterised by the occurrence of populations with higher frequencies of parental types than would be expected by recombination. In type (b) hybrid zones, some populations will consist entirely or predominantly of hybrids, with parental types occurring as a result of recombination or migration. It is possible that high levels of parental immigration may result in type (b) hybrid zones resembling type (a) hybrid zones.

Both types of hybrid zone represent evolutionary stalemates, in that further divergence of the interacting populations may occur only slowly. In a zone of hybrid disadvantage, evolution of reproductive character displacement (Brown and Wilson, 1956) and ecological differentiation (Mayr, 1963), which together would allow broad geographic overlap, are prevented. Firstly, such mechanisms would be favoured by selection only in the area of interaction, where an individual's fitness is lowered by any mating with other than a conspecific individual. Secondly, continuing immigration of individuals from parental populations adjacent to the zone of interaction would result in " genetic swamping" of the products of reinforcing selection (Thaeler, 1968; Littlejohn, 1969; Watson, 1972).

Those zones in which hybrids are fitter than either parental type presumably occur in ecotonal areas, in which the intermediate character of the hybrids makes them better adapted than the parental types (Hagen, 1967; Montanucci, 1970; Hunt and Selander, 1973). These hybrid zones could persist for as long as the environment favours the hybrid phenotypes.

The width of hybrid zones can vary geographically (e.g. Hunt and Selander, 1973), and their location may alter with time (McDonnell, Gartside and Littlejohn, 1978) in response to changing selective gradients, either environmental, genetic, or both.

More data are needed to test the generality of these hypotheses, and to elucidate the nature and evolutionary dynamics of hybrid zones. Towards this end, data have been gathered over more than 10 years on an interaction between Geocrinia laevis* (Gunther) and G. victoriana (Boulenger) in southwestern Victoria. The biology and general distribution of these taxa were described by Littlejohn and Martin (1964). Although G. laevis and G. victoriana are morphologically indistinguishable, they have different breeding calls. Females from allopatric populations adjacent to the hybrid zone efficiently discriminate between the breeding calls of the two species, and are attracted to that of a conspecific male (Littlejohn and Watson, 1974). Despite large differences in this important potential selective mating system, the two taxa hybridise along a zone which is less than $11 \mathrm{~km}$ wide (Littlejohn, Watson and Loftus-Hills, 1971; Littlejohn and Watson, 1973). A putative natural hybrid breeding call, consisting of a mosaic of parental calls, attracted females of both taxa (Littlejohn and Watson, 1976a). The inability of "pure" individuals of each taxon to discriminate between conspecific breeding calls and those of hybrids, together with a high degree of genetic compatibility in all crosses (Littlejohn, Watson and Loftus-Hills, 1971), are important factors in the maintenance of the narrow hybrid zone. The composition, width and position of the hybrid zone based on breeding calls did not change at one locality during an intensive 7-year study (Littlejohn and Watson, $1976 b$ and unpub. obs.).

It appears from these data that $G$. laevis and $G$. victoriana are biological

* Removed from Crinia by Blake (1973). 
species. Despite apparently random mating in the area of contact, hybridisation based on call characters is restricted to a narrow zone. The species are distinct outside the area of contact and are characterised by marked differences in other aspects of breeding behaviour, as well as in breeding calls (M. J. Littlejohn, G. F. Watson and P. Harrison, unpub. obs.).

Although the breeding calls of these species probably are polygenically inherited (Littlejohn and Watson, 1976b), and so represent many genes, it is important to base evolutionary studies on as many independently determined characters as possible. In the present study, a transect was established across the hybrid zone. In addition to an analysis of variation in breeding calls along this transect, a comparative study was made of protein variation to provide additional characters for identification of the two species and hybrids, and to further elucidate the structure and position of the hybrid zone.

\section{Methods}

\section{(i) Collection of population samples}

For electrophoretic analysis, 173 individuals (149 males; 24 females) were collected during the breeding season (April and May) in 1977, and 286 individuals (271 males; 15 females) during the breeding season in 1978. These individuals were collected from a total of 18 localities in southwestern Victoria (fig. 1). All specimens analysed were sexually mature. These localities form an approximate right-angled transect, based on the

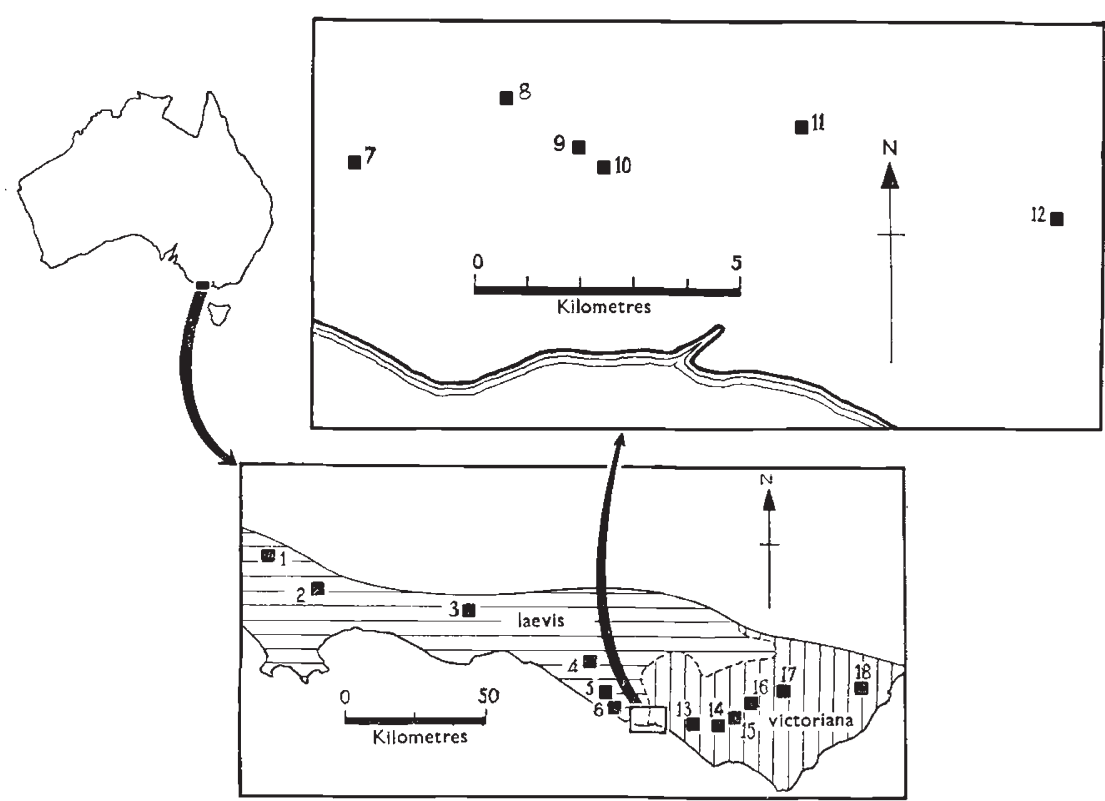

F1G. 1.-Collecting sites for the $G$. laevis complex in south-western Victoria. The shaded areas indicate the approximate distributions of $G$. laevis (horizontal lines) and $G$. victoriana (vertical lines). The dashed line shows the estimated position of the breeding call hybrid zone. 
distribution of breeding calls, of the southern area of the hybrid zone between Geocrinia laevis and G. victoriana (Littlejohn, Watson and Loftus-Hills, 1971). To reduce any distortion of the distance relationships of localities relative to the breeding call hybrid zone due to dis placement of some localities from the direct linear transect, distances between localities in later comparisons were calculated as the direct distance $(\mathrm{km})$ of each locality from Locality 1 (fig. 1). This method necessarily introduces an error for distance between localities when determining widths of replacement zones. It is less severe, however, than that which would occur if distances were calculated by adding the direct geographic distance from one locality to the next. Breeding calls of 81 individuals were tape recorded at nine localities in the months of April and May between 1972 and 1975.

\section{(ii) Electrophoretic technique}

Electrophoresis was performed on horizontal 5 per cent acrylamide gel slabs at $4 \pm 2 \mathrm{C}$. Individuals from distant allopatric populations of each taxon (Localities 1 and 2 for $G$. laevis, Localities 17 and 18 for G. victoriana) (fig. 1), were examined for electrophoretic differences in enzymic and nonenzymic proteins encoded by at least 26 presumed genetic loci, to determine if any proteins were taxonomically diagnostic. Tissue homogenates from individuals from these populations subsequently were run on each gel as reference samples.

The proteins studied were lactate dehydrogenase; malate dehydrogenase; glutamate dehydrogenase; alkaline phosphatase; acid phosphatase; glutamic oxaloacetic transaminase; phenylalanyl proline-, valyl leucine-, and leucyl glycyl glycine peptidase; tetrazolium oxidase; $\alpha$ naphthyl acetate-, $\beta$ naphthyl acetate-, $\alpha$ naphthyl proprionate-, and methyl umbelliferyl acetate esterases; leucine amino peptidase; catalase; peroxidase; and general plasma and muscle proteins stained with amidoschwarz. Specific staining techniques follow those described by Shaw and Prasad (1970) and Dessauer, Nevo and Chuang (1975).

Staining for each protein system was attempted in homogenates of heart muscle, skeletal muscle and liver; in red blood cell haemolysates and in plasma, to determine the tissue which gave the best resolution of each protein, and whether different electromorphs occurred in different tissues. Tissues were collected from freshly killed animals. The tissue extracts were prepared by homogenising a mixture of equal volumes of tissue and distilled water, then centrifuging at $1000 \times g$ for 10 minutes. Fifteen $\mu \mathrm{l}$ aliquots of supernatant were then inoculated directly into preformed slots in the gel for electrophoresis.

Two electrophoretic buffers were tested: Poulik's (1957) discontinuous tris-citrate/sodium borate buffer, and a continuous sodium borate buffer $0 \cdot 13 \mathrm{M}$ boric acid, $p \mathrm{H} 8 \cdot 6$. A preliminary analysis of proteins was made using Poulik's buffer. Those proteins which showed possible differences between the taxa, or poor resolution in Poulik's buffer, were further tested in the sodium borate buffer. Because it gave good resolution of taxonomically conservative proteins, the sodium borate $p \mathrm{H} 8 \cdot 6$ buffer was used in all subsequent analyses. Electrophoresis was continued for 2 hours at a constant voltage gradient of 12.5 volts $/ \mathrm{cm}$ along the gel. 


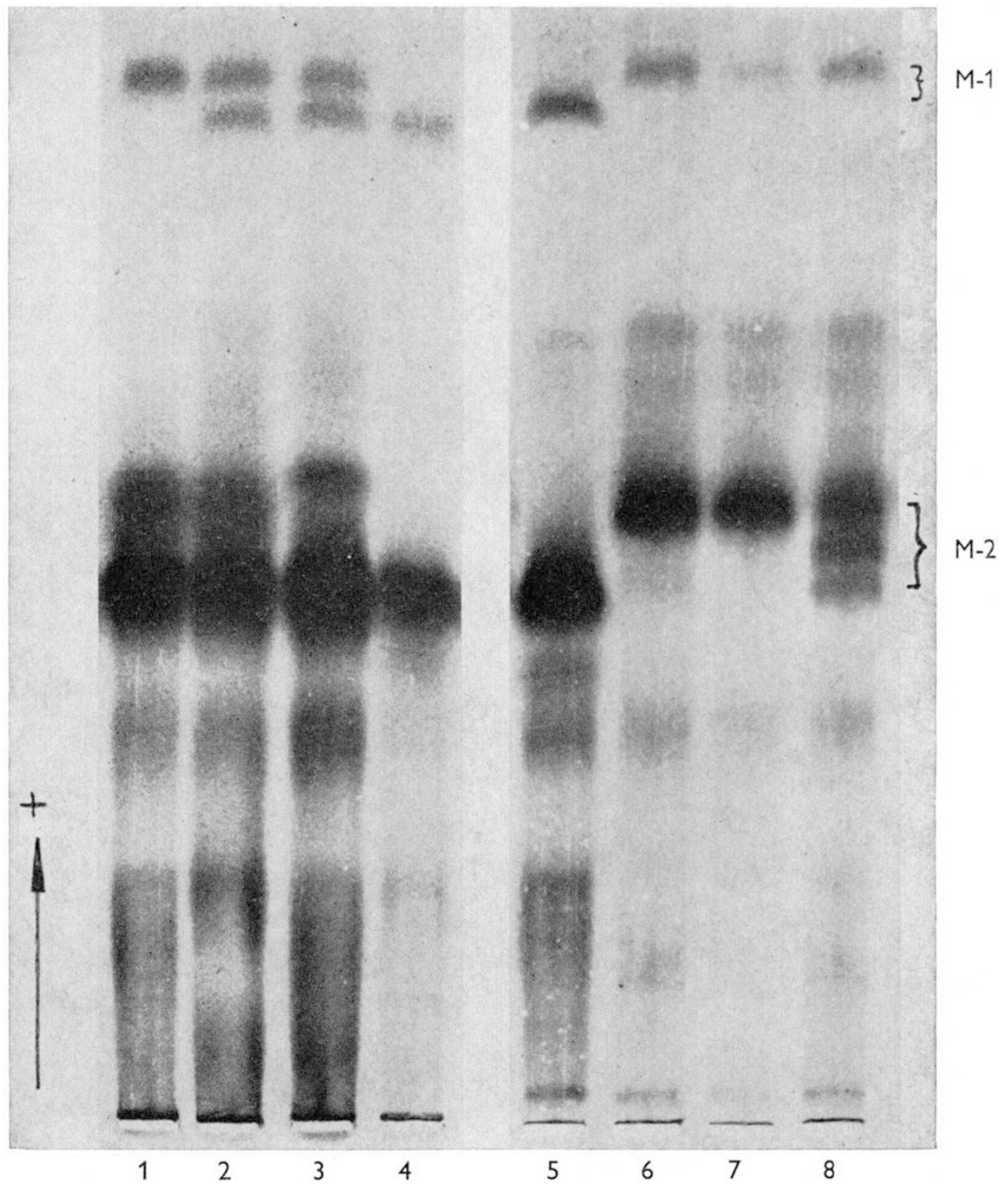

FIG. 2.-Electrophoretic phenotypes of muscle proteins. $1=\mathrm{M}-1^{a} ; 2$ and $3=\mathrm{M}-1^{a / b}$; $4=\mathrm{M}-\mathrm{1}^{b}\left(1-4\right.$ all $\left.\mathrm{M}-2^{b}\right), 5=\mathrm{M}-1^{b}, \mathrm{M}-2^{b} ; 6$ and $7=\mathrm{M}-2^{a} ; 8=\mathrm{M}-2^{a / b}(6,7$ and 8 all $\left.\mathrm{M}-\mathrm{1}^{a}\right)$. There is a band of slightly faster mobility than that encoded by $\mathrm{M}-2^{a}$ in slots 1, 2 and 3. This band occurred in samples only from some localities, and always was distinguishable from phenotypes at the $\mathrm{M}-2$ locus. 
(iii) Recording and analysis of male breeding calls

Breeding calls were tape recorded in the field with a Nagra III BH tape recorder and a Beyer M 88 microphone. Frogs called from concealed sites in grass and litter, and wet-bulb air temperatures were taken near males whose calls were recorded; these temperatures are presumed to approximate those of small frogs calling on land.

Tape recordings were analysed on an audiospectrograph (Kay Elemetrics 6061-B Sona-Graph), with playback on a Tandberg 11-2 tape recorder. Where necessary, tapes were replayed at one-half or one-quarter speed to increase temporal resolution of wide-band (filter setting $300 \mathrm{~Hz}$ bandpass) audiospectrograms. Frequency responses of all electronic components are substantially linear within the relevant range of frequencies (based on manufacturers' specifications), and variations in tape speed were less than $\pm 1 \cdot 5$ per cent.

The breeding calls, which have been described by Littlejohn and Martin (1964) and Littlejohn, Watson and Loftus-Hills (1971), are diphasic, and consist of one (or occasionally two or three) longer introductory note, followed by a series of shorter repeated notes. Pulse repetition rates of introductory and repeated notes were selected for detailed study because there were marked differences in both characters between the calls of parental species.

Values for pulse repetition rates were obtained as follows (after Littlejohn and Watson, 1973):

Introductory note-duration ( $\pm 5 \mathrm{~ms}$ ), number of pulses ( \pm 1 pulse), and pulse repetition rate (as $n-1$ pulses $\times 100$ /duration in $\mathrm{ms}$ ), were determined for the first introductory note in one call in the recorded call sequence (generally the last call). Repeated notes-pulse repetition rates of three successive notes in the same call of each male were determined by the same method as for the introductory note, the notes being selected near the middle of the sequence to maximise variability.

Wet-bulb air temperatures at the calling sites ranged from 9.8 to $14.5 \mathrm{C}$, and because of this narrow range, no attempt was made to correct for this variable.

\section{(iv) Statistical and numerical procedures}

The unbiased method of Levene (1949) was used to calculate expected numbers of genotypes for testing goodness of fit to Hardy-Weinberg equilibrium. Other statistical procedures follow Sokal and Rohlf (1969). Presumed gene frequencies were calculated directly from phenotypes scored from gels. The graphical presentation of frequencies follows that of Jamieson (1975).

\section{Results}

\section{(i) Protein analysis}

Preliminary analyses of protein variation in samples of Geocrinia laevis and G. victoriana collected at distant allopatric localities (Locs. 1 and 2; 17 and 18, fig. 1), revealed only two protein systems which consistently distinguished the two species, and so could be used as diagnostic characters, and for 
identification of hybrids. Further electrophoretic analyses were confined to these systems.

Both systems are skeletal muscle proteins detected with a general protein stain (amidoschwarz 10B, Ghroma Gesellschaft). Each system appears to be determined by a single locus with two codominant alleles. The fastermigrating system is termed $M-1$, and the slower-migrating system, $M-2$. The "allele" encoding the most anodally-migrating band in each system is termed $a$, and is fixed in the two distant allopatric samples of $G$. laevis (Localities 1 and 2, fig. 1). The " allele " encoding the slower-migrating band is termed $b$, and is fixed in the two distant allopatric samples of $G$. victoriana (Localities 17 and 18, fig. 1). Hence, distant allopatric G. laevis have the presumed genotype $\mathrm{M}-\mathrm{l}^{\alpha / a}, \mathrm{M}-2^{a / a}$ and distant allopatric $G$. victoriana have $\mathrm{M}-1^{b / b}, \mathrm{M}-2^{b / b}$.

Phenotypes classified as being encoded by $\mathrm{M}-\mathrm{I}^{b}$ may include bands which differ slightly in mobility. Some individuals appeared to have a marginally faster-migrating band than the most commonly-occurring one, but because the mobility difference could not be resolved consistently on re-runs of these samples, and it was not possible to recognise presumed heterozygous phenotypes, these bands are considered as a single phenotype for population analysis. This combined $M-1^{b}$ phenotype was distinct in

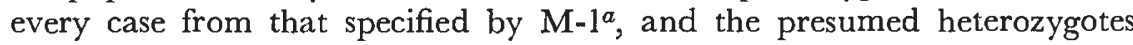
M-1 ${ }^{a / b}$ could be scored unambiguously (fig. 2). Presumed homozygous phenotypes for both M-l and M-2 are one-banded. The presumed heterozygous phenotype for $\mathrm{M}-1$ is two-banded, each band staining with approximately equal intensity, which suggests the protein may be a monomer. The presumed heterozygous phenotype for $\mathrm{M}-2$ is three-banded, the intensity of staining of the bands approximating a $1: 2: 1$ ratio, which is consistent with the protein being a dimer. Gene frequencies for two muscle-protein loci are shown in fig. 3. Protein phenotypes in samples from each locality
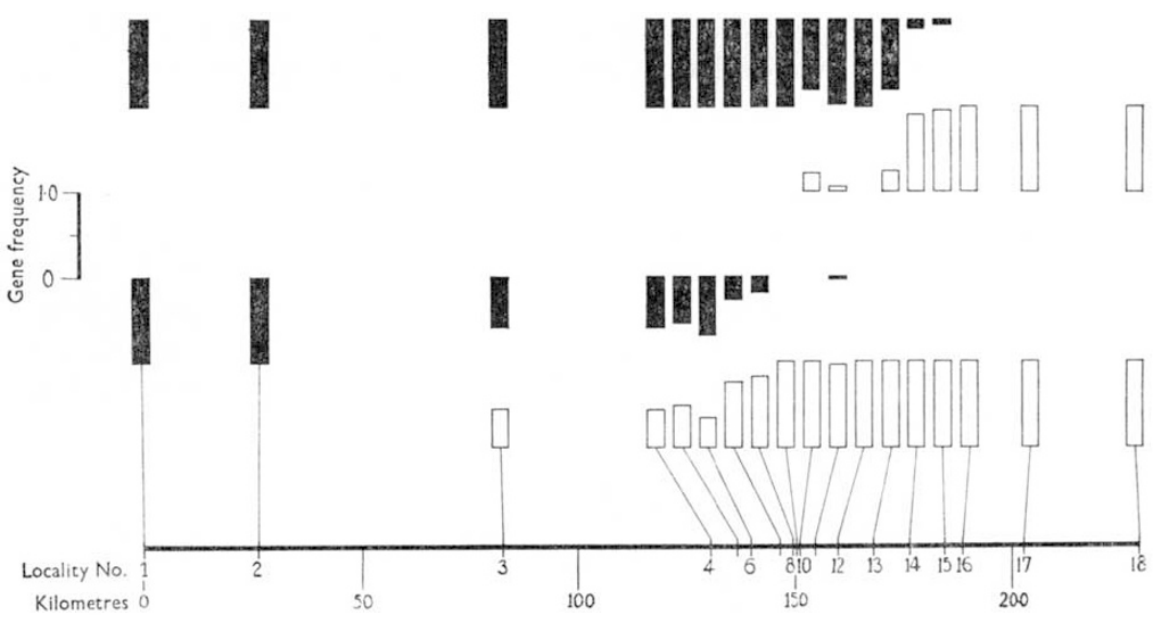

FIG. 3.-Presumed gene frequencies for loci encoding muscle proteins. The upper two rows of boxes represent $M-1$; the shaded boxes are frequency of $M-1^{a}$ the unshaded boxes $\mathrm{M}-\mathrm{I}^{b}$. The lower two rows of boxes represent $\mathrm{M}-2$; the shaded boxes show the frequency of $M-2^{a}$ in each sample, the unshaded boxes, the frequency of $M-2^{b}$. 
did not differ significantly from numbers expected at Hardy-Weinberg equilibrium.

\section{(ii) Breeding call analysis}

Values for pulse repetition rates of introductory and repeated notes are presented in fig. 4. The arbitrary limits for pulse repetition rates of introductory and repeated notes, used by Littlejohn and Watson $(1973,1976 b)$

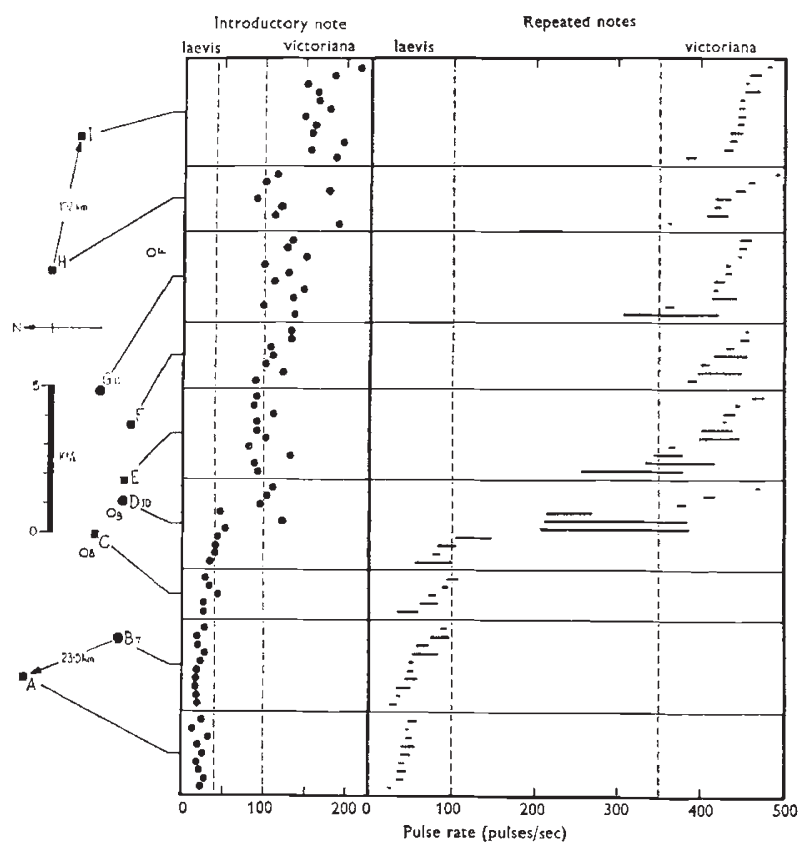

FIG. 4.--Recording sites for samples of the G. laevis complex, and data for introductory and repeated notes of breeding calls. Dots represent values for pulse rates of introductory note, horizontal lines represent range of variation for pulse rate of three successive repeated notes for each individual. The broken vertical lines indicate arbitrary limits for parental samples. Shaded symbols represent recording localities; squares are localities where breeding call samples only were obtained; closed circles are localities at which both protein samples and recordings were obtained. Open circles show the positions of localities across the breeding call hybrid zone where protein samples only were obtained.

for diagnosis of breeding calls of putative parental males, also were employed in the present study. The upper limits for $G$. laevis are: introductory note$40 \mathrm{pulses} / \mathrm{s}$; repeated notes-100 pulses/s; and the lower limits for $G$. victoriana are: introductory note-100 pulses/s; repeated notes $-350 \mathrm{pulses} / \mathrm{s}$. Values falling between these limits are presumed to reflect hybridity in the individual producing these calls, and may be intermediate, close to, or may overlap, one of the parental limits.

To facilitate interpretation, a simplified hybrid index was constructed, following the method of Littlejohn and Watson (1973), with scores arranged so that similarity to $G$. laevis was indicated by a low value (with a minimum of 0 ), and to $G$. victoriana with a high value (with a maximum of 8 ) (tables 1 and 2). Because many of the recording localities are different to localities at which samples were collected for protein analysis, the recording sites have 
been designated by the letters A-I (table 2). Only three of these localities coincide with protein localities: $\mathrm{B}=7, \mathrm{D}=10$ and $\mathrm{G}=11$.

It is evident from table 2 and figs. 4 and 5 that the region of steepest transition occurs between Localities $\mathrm{G}$ and $\mathrm{E}$, with both parental types and a wide array of putative hybrids at Locality $\mathrm{D}$. Localities $\mathrm{A}$ and $\mathrm{B}$ consist only of $G$. laevis, and Locality I only of $G$. victoriana. There is a low level of putative hybridity at Localities $F, G$ and $H$, being reflected mainly in pulse repetition rates of introductory notes.

\section{TABle 1}

Construction of hybrid index scores from breeding call components of individuals. Hybrid index of $0=\mathrm{G}$. laevis; $8=\mathrm{G}$. victoriana

Call Component

Pulse repetition rate of introductory note (pulses/s)

Pulse repetition rates of repeated notes (pulses/s)

State of Component

Score

$\begin{array}{ll}\leqq 40 & 0 \\ 41-60 & 1 \\ 61-80 & 2 \\ 81-99 & 3 \\ \geqq 100 & 4\end{array}$

$\begin{array}{cc}\text { All } \leqq 100 & 0 \\ \text { All }<350, \text { one or two } \leqq 100 & 1 \\ \text { All }>100<350 & 2 \\ \text { All }>100, \text { one or two } \geqq 350 & 3 \\ \text { All } \geqq 350 & 4\end{array}$

TABle 2

Numbers of individuals at each locality with each hybrid index value based on pulse repetition rates of introductory and repeated notes of breeding calls. See text for explanation.

Locality G. laevis

(and grid reference)*

A

(57142651)

B

(58282411)

C

(58732416)

D

(58792410)

E

(58852408)

$\mathrm{F}$

(59102408)

G

(59192422)

$\mathrm{H}$

(59632436)

I

(61582400)
Hybrid index score

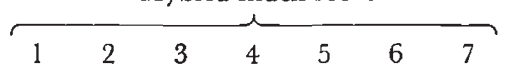

G. victoriana

8

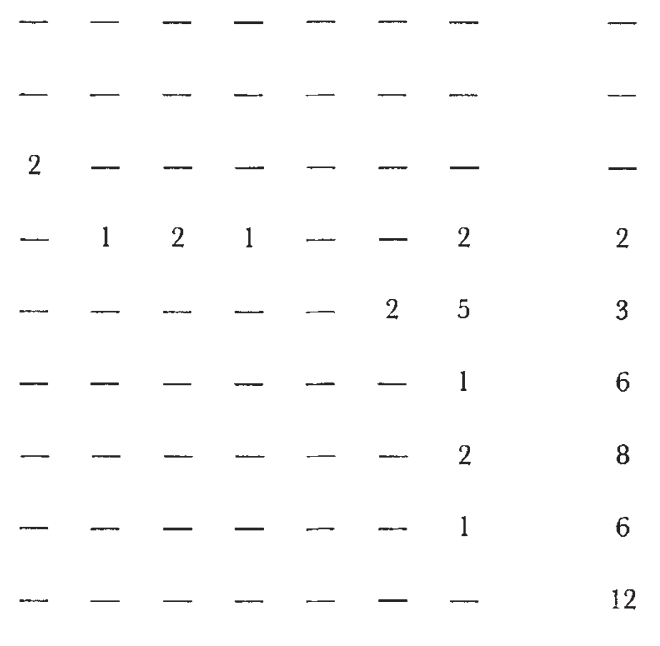

* Derived from Royal Australian Survey Corps map: Australia 1:250,000; Colac SJ 54-12, Edition 1, 1968, with a fourth figure added to each co-ordinate to increase precision. 


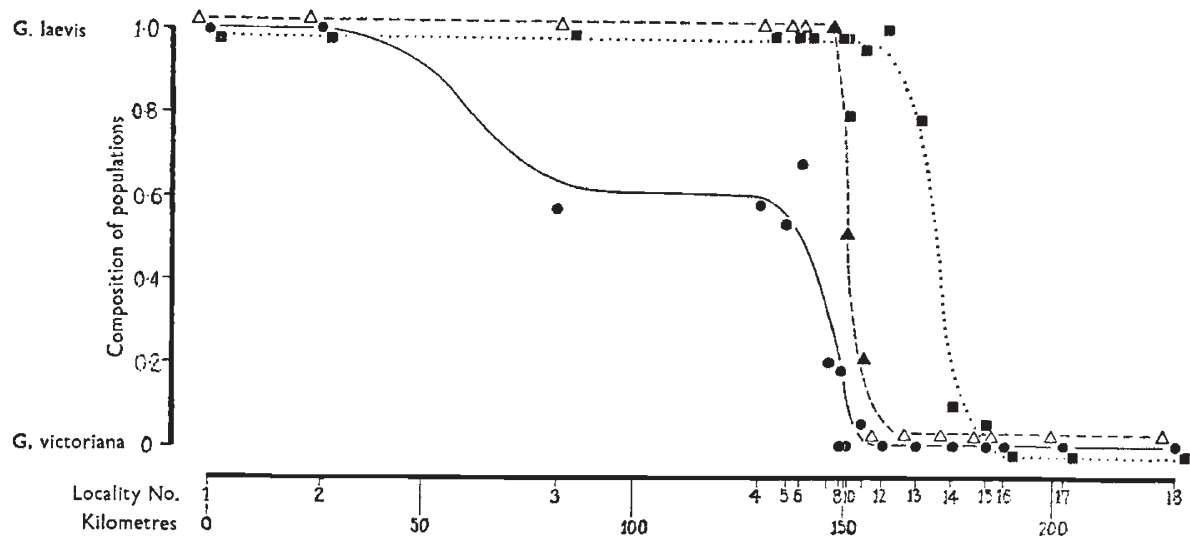

Frg. 5.-Replacement zones for M-2 (solid line), breeding call (dashed line) and M-1 (dotted line). For $\mathrm{M}-2$, the circles represent the gene frequency of $M-2^{a}$ at each locality. For breeding call, the unshaded triangles represent estimated composition of populations based on subjective acoustic assessments; the shaded triangles are estimates of population composition based on mean hybrid index scores derived from recording analysis; only recording localities which are coincidental with protein localities are shown. The square symbols represent the frequency of $\mathrm{M}-\mathrm{I}^{a}$ in samples from each locality.

\section{(iii) Analysis of replacement zones}

The zone of replacement for breeding calls is very narrow, and the transition from one species to the other forms a smooth, very steep cline (fig. 5). The minimum width of replacement (the last locality at each edge of the transition area at which elements of both breeding calls occur) is approximately $9 \mathrm{~km}$ (Localities $\mathrm{C}-\mathrm{H}$, fig. 4; Localities 8-12, fig. 6); the maximum width (the first locality outside each margin of the transition area

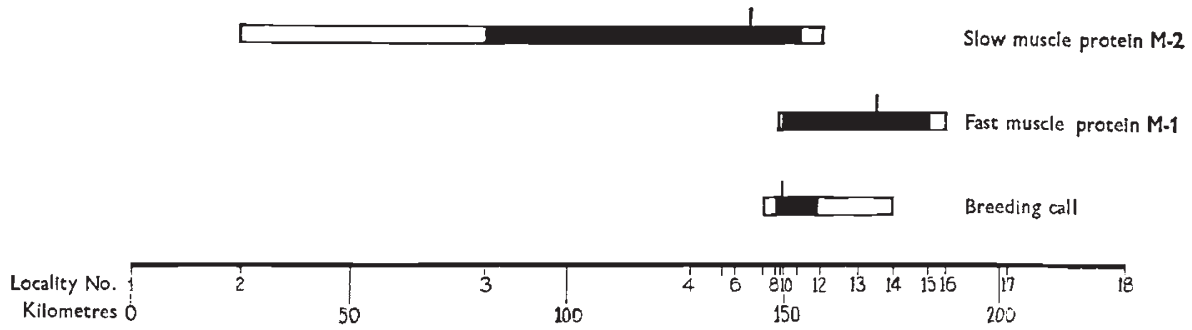

Frg. 6.-Maximum (unshaded boxes) and minimum (shaded boxes) estimated widths of replacement zones. The vertical line indicates the estimated centre of each transition zone based on equivalence of gene frequency for muscle proteins, or highest frequency of hybrids, for breeding calls (table 2).

at which only "pure " breeding calls of $G$. laevis and $G$. victoriana occur), is approximately $30 \mathrm{~km}$ (Localities B-I, fig. 4; Localities 7-14, fig. 6). The transition is asymmetrical, with the estimated mid-point (the sample in which the $G$. laevis and $G$. victoriana components are approximately equal) nearer the $G$. laevis (western) margin of the zone (fig. 6).

The zone of replacement of M-1 is also narrow, although the cline has a 
small area of discontinuity towards its western margin (fig. 5), approximately coinciding with the position of the zone of replacement for breeding calls. The minimum width of replacement for M-1 (the last locality at the edge of the transition area at which both alleles for the muscle protein occur), is approximately $33 \mathrm{~km}$ (Localities 9-15, fig. 6); the maximum width (the first locality outside each margin of the transition area at which the muscle protein becomes fixed for one of the alleles), approximately $38 \mathrm{~km}$ (Localities 8-16, fig. 6). A slight asymmetry is also apparent in the zone of replacement for M-1, but the "null-point" (the estimated point of gene frequency equivalence, e.g. $\left.\mathrm{M}-\mathrm{I}^{a}=\mathrm{M}-\mathrm{I}^{b}=0.5\right)$ is slightly nearer the $G$. victoriana (eastern) margin of the transition (fig. 6).

For M-2, the zone of replacement is much wider than for the other two characters, and the nature of the transition is more complex (fig. 5). The transition from protein characteristic of $G$. laevis $\left(\mathrm{M}-2^{a}\right)$ begins as a very shallow cline which tapers into a plateau, but becomes very steep in approximately the same position as the replacement zone for breeding calls, and the $G$. victoriana edge for these two replacement zones coincides. The minimum width of replacement for M-2 is approximately $72 \mathrm{~km}$ (Localities 3-11, fig. 6); the maximum width, approximately $134 \mathrm{~km}$ (Localities 2-12, fig. 6). The replacement is markedly asymmetrical, with the "null-point" closer to the $G$. victoriana margin of the transition.

None of the individuals in the present study were double heterozygotes $\left(\mathrm{M}-1^{a / b}, \mathrm{M}-2^{a / b}\right)$, i.e. could have been presumed $\mathrm{F}_{1}$ hybrids based on the marker proteins (table 3 ). This is primarily due to the low level of overlap of the replacement zones for M-1 and M-2 (fig. 5).

TABLE 3

Frequency of individuals with each presumed genotype observed for the two muscle proteins at sample localities. $\mathcal{N}$ is the sample size. Locality numbers refer to localities in the text and figures.

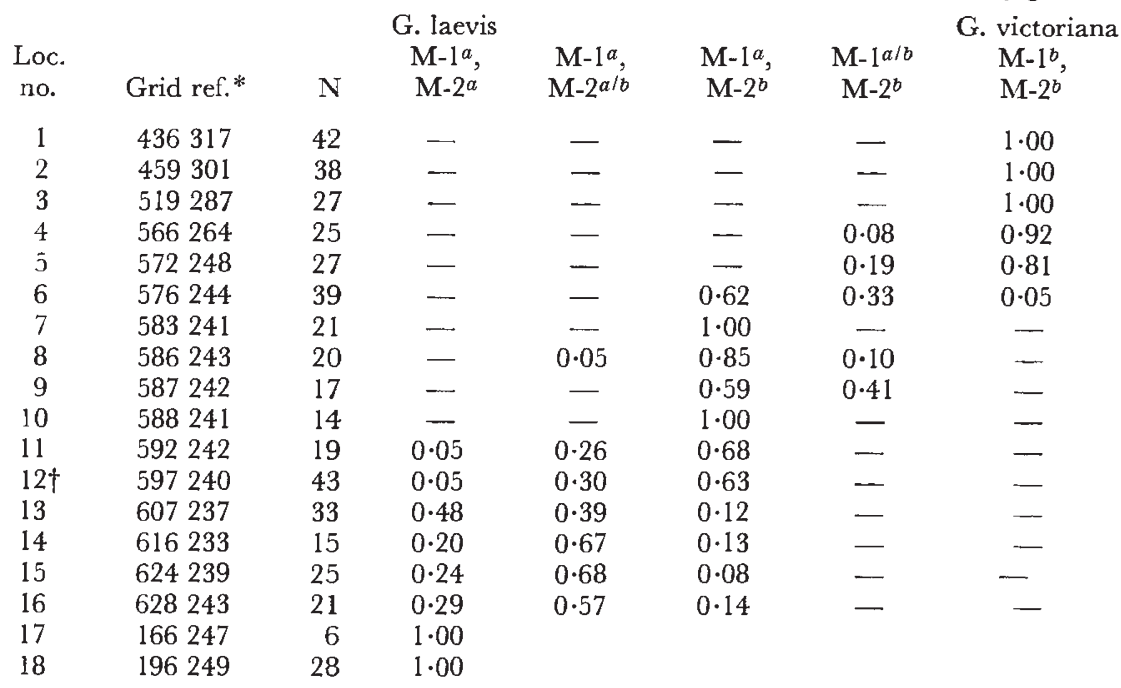

* Derived from Royal Australian Survey Corps maps : Australia 1 : 250,000; Colac SJ 54-12, Portland SJ 54-11 and Hamilton SJ 54-7, Edition 1, 1968.

$\uparrow$ Samples from 1977 and 1978 are combined: they do not differ significantly $\left(\chi_{2}^{2}=3.0880 .5>p>0 \cdot 1\right)$ when treated with a G-test (Sokal and Rohlf, 1969). 


\section{Discussion}

The interaction between Geocrinia laevis and $G$. victoriana is unusual because the zones of replacement of the three diagnostic characters examined differ not only in width, but also in their geographic locations (figs. 5 and 6). The extent of geographic overlap shown in fig. 6 contains a much lower level of genetic overlap, in that only the "tails" of the clines for each character are involved.

There are different ways in which this situation may have evolved.

(1) The interaction between the species may be a "stable" one, i.e. have reached, or be in the last stages of asymptotic approach towards a geographic equilibrium position. The present position of the replacement zones for the two muscle proteins relative to the replacement zone for breeding calls might then have been produced in either of the following ways :

(a) The diagnostic proteins were once absolutely associated with each of the breeding call types, i.e. differentiation of the protein types occurred prior to speciation, or contemporaneously with the speciation process (no assumption is necessary for whether speciation occurred in situ by the allopatric model, e.g. Mayr, 1963). The present position of the muscle protein replacement zones then would represent differential introgression through a breeding call hybrid zone, with different selective factors determining their positions independently of one another, and of the hybrid zone. Introgression between $G$. laevis and $G$. victoriana could be expected to occur because there appears to be unrestricted hybridisation in the breeding call replacement zone, and there is little, if any, genetic incompatibility between the species (Littlejohn, Watson and Loftus-Hills, 1971).

(b) The muscle protein clines formed independently of speciation in $G$. laevis and $G$. victoriana and occupy their present positions in the same general area as the breeding call hybrid zone because there is, or recently was, a major ecotone in that area, different selective components of which affect the distribution of the species, and the proteins.

(2) The zone of interaction between $G$. laevis and G. victoriana may be moving (or have recently moved). This shift might occur if the environment were changing, or if there had been insufficient time for the species interaction to have reached an equilibrium point. Different components of the genome of one species $(G$. laevis) could then be advancing at different rates depending on their interaction with the external environment and/or the genome of the other species.

It is not possible to distinguish between these hypotheses on the basis of the present data. Although some studies have shown that asymmetry of a replacement zone occurred where the zone of interaction was moving (Burton and Martin, 1976; McDonnell, Gartside and Littlejohn, 1978), the generality of these observations has yet to be demonstrated. Indeed, there is evidence that the breeding-call replacement between $G$. laevis and $G$. victoriana about half-way along the zone has remained in the same position for at least 7 years (Littlejohn and Watson, 1976b), and probably even longer (Littlejohn, Watson and Loftus-Hills, 1971).

Based on breeding-call composition of samples (fig. 4), the nature of the interaction between $G$. laevis and $G$. victoriana varies in different parts of the 
hybrid zone. Most populations from the northern area consist primarily of hybrids (Littlejohn and Watson, 1976b) or of hybrids and only one or other of the parental types (Littlejohn, Watson and Loftus-Hills, 1971 ; Littlejohn and Watson, 1974). In contrast, the present study shows overlap of the parental types in the zone of interaction (Locality D, table 2, fig. 4). This finding suggests that there is a change in the factors determining the composition and dynamics of the zone of interaction in different areas, or that contact has been more recent in one area than in another.

Most of the transition in breeding calls across the southern transect occurs over about $10 \mathrm{~km}$ (fig. 5), as in other areas of the interaction (Littlejohn, Watson and Loftus-Hills, 1971 ; Littlejohn and Watson, 1973). This observation is consistent with the overall width of the interaction being determined by the vagility of the animals, while the composition of samples reflects the selective regimes, migration patterns, and history of contact in different parts of the range.

There is presently no observational evidence for a difference in environmental characteristics in different areas of the zone of interaction, and if the zone aligns along an ecotone, it is presumably a subtle one representing a complex balance point influenced by many environmental factors, rather than by a steep gradient in a single major environmental factor (Littlejohn, Watson and Loftus-Hills, 1971).

Whichever factors are important in accounting for the different composition of populations in different areas of the hybrid zone, it is clear that this hybrid zone is not amenable to any one of the classifications proposed by Woodruff (1973) or Moore (1977). The complexity of the interaction between $G$. laevis and $G$. victoriana emphasises the need for a broad approach over a long term in studies of such evolutionary phenomena.

Acknowledgments.-We thank Gael Gartside, Peter Harrison and Peter Robertson for assistance with field work and are grateful to Dr C. M. Bull, Dr G. M. Hewitt and Dr D. D. Shaw for their constructive comments on the manuscript. This research was supported by A.R.G.C. grants D66/16172 and D17715598 and funds from the University of Melbourne standing research vote.

\section{REFERENGES}

ALEXANDER, R. D., AND BIGELOW, R. S. 1960. Allochronic speciation in field crickets, and a new species Acheta veletis. Evolution, 14, 334-346.

ANTonovics, J. 1971. The effects of a heterogeneous environment on the genetics of natural populations. Amer. Sci., 59, 593-599.

BLAKE, A. J. D. 1973. Taxonomy and relationship of myobatrachine frogs (Leptodactylidae): a numerical approach. Aust. F. Zool., 21, 119-149.

BRown, w. L., AND wilson, E. o. 1956. Character displacement. Syst. Zool., 5, 49-64. BURTON, T. G., AND MARTin, A. A. 1976. Analysis of hybridization between black-backed and white-backed magpies in south-eastern Australia. The Emu, 76, 30-36.

Bush, G. L. 1969. Sympatric host race formation and speciation in frugivorous flies of the genus Rhagoletis (Diptera, Tephritidae). Evolution, 23, 237-251.

Dessauer, H. G., Nevo, E., AND GHUANG, K-C. 1975. High genetic variability in an ecologically variable vertebrate, Bufo viridis. Biochem. Genet., 13, 651-661.

Dobzhansky, т. 1970. Genetics of the Evolutionary Process. Columbia University Press, New York.

ENDLER, J. A. 1973. Gene flow and population differentiation. Science, 179, 243-250.

ENDler, J. A. 1977. Geographic Variation, Speciation and Clines. Population Biology Monograph 10. Princeton University Press, Princeton, New Jersey. 
HAGEN, D. W. 1967. Isolating mechanisms in three spine sticklebacks (Gasterosteus). 7. Fish. Res. Bd. Canada, 24, 1673-1692.

HUNT, W. G., AND SELANDER, R. K. 1973. Biochemical genetics of hybridisation in European house mice. Heredity, 31, 11-33.

JAIN, S. K., AND BRADSHAW, A. D. 1966. Evolutionary divergence among adjacent plant populations. I. Evidence and its theoretical analysis. Heredity, 21, 407-442.

Jamieson, A. 1975. Enzyme types of Atlantic cod stocks on the North American banks. In Isozymes: Genetics and Evolution, ed. C. L. Markert, pp. 491-515. Academic Press, New York.

LEVENE, н. 1949. On a matching problem arising in genetics. Ann. Math. Stat., 20, 91-94.

LITTLEJOHN, M. J. 1969. The systematic significance of isolating mechanisms. In Systematic Biology: Proceedings of an International Conference, pp. 459-482. Nat. Acad. Sci., Washington D.C.

irttlejohn, m. J., AND martin, A. A. 1964. The Crinia laevis complex (Anura: Leptodactylidae) in south-eastern Australia. Aust. F. Zool., 12, 70-83.

LITTLEJOHN, M. J., AND WATSON, G. F. 1973. Mating-call variation across a narrow hybrid zone between Crinia laevis and C. victoriana (Anura: Leptodactylidae). Aust. F. Zool., 21, 277-284.

LITTLEJOHN, M. J., AND WATSON, G. F. 1974. Mating call discrimination and phonotaxis by females of the Crinia laevis complex (Anura: Leptodactylidae). Copeia, 1974, 171-175.

LITTLEJOHN, M. J., AND WATSON, G. F. 1976a . Effectiveness of a hybrid mating call in eliciting phonotaxis by females of the Geocrinia laevis complex (Anura: Leptodactylidae). Copeia, 1976, 76-79.

LITTLEJOHN, M. J., AND WATsON, G. F. 1976b. Mating-call structure in a hybrid population of the Geocrinia laevis complex (Anura: Leptodactylidae) over a seven-year period. Evolution, 30, 848-850.

LITTLEJOHN, M. J., WATSON, G. F., AND LOFTUS-HILls, J. J. 1971. Contact hybridization in the Crinia laevis complex (Anura: Leptodactylidae). Aust. F. Zool., 19, 85-100.

MCDONNELL, L. J., GARTSIDE, D. F., AND LITTLEJOHN, M. J. 1978. Analysis of a narrow hybrid zone between two species of Pseudophryne (Anura: Leptodactylidae) in southeastern Australia. Evolution, 32, 602-612.

MAYR, E. 1963. Animal Species and Evolution. Belknap Press of Harvard University Press, Cambridge, Massachusetts.

MONTANUCCI, R. R. 1970. Analysis of hybridization between Crotaphytus wislizenii and Crotaphytus silus (Sauria: Iguanidae) in California. Copeia, 1970, 104-123.

MOORE, w. s. 1977. An evaluation of narrow hybrid zones in vertebrates. Quart. Rev. Biol., 52, 263-277.

PouliK, M. D. 1957. Starch gel electrophoresis in a discontinuous system of buffers. Nature, 180, 1477-1479.

SHAW, G. R., AND PRASAD, R. 1970. Starch gel electrophoresis of enzymes-A compilation of recipes. Biochem. Genet., 4, 297-320.

SHORT, L. L. 1969. Taxonomic aspects of avian hybridization. Auk, 86, 84-105.

sokal, R. R., AND Rohlf, F. J. 1969. Biometry: The Principles and Procedures of Statistics in Biological Research. W. H. Freeman, San Francisco.

THAELER, C. S. 1968. An analysis of three hybrid populations of pocket gophers (genus: Thomomys). Evolution, 22, 543-555.

WATson, G. F. 1972. The Litoria ewingi complex (Anura: Hylidae) in south-eastern Australia II. Genetic incompatibility and delimitation of a narrow hybrid zone between L. ewingi and L. paraewingi. Aust. F. Zool., 20, 423-433.

woodRufF, D. s. 1973. Natural hybridisation and hybrid zones. Syst. Zool., 22, 213-218. 